Research Article

\title{
Effective Factors in Critical Thinking Disposition in Nursing Students
}

\author{
Noushin Mousazadeh $\left(\mathbb{D},{ }^{1}\right.$ Marzieh Momennasab $\left(\mathbb{D},{ }^{2}\right.$ Hamid Sharif Nia $\left(\mathbb{D},{ }^{3}\right.$ \\ Roghieh Nazari $\mathbb{D}^{1}{ }^{1}$ and Fatemeh Hajihosseini $\mathbb{D D}^{1}$ \\ ${ }^{1}$ Department of Nursing, Amol Faculty of Nursing and Midwifery, Mazandaran University of Medical Science, Sari, Iran \\ ${ }^{2}$ Department of Nursing, School of Nursing and Midwifery, Shiraz University of Medical Sciences, Shiraz, Iran \\ ${ }^{3}$ Education Development Center, Mazandaran University of Medical Science, Sari, Iran
}

Correspondence should be addressed to Fatemeh Hajihosseini; f.hajihosseini@mazums.ac.ir

Received 14 January 2021; Revised 6 July 2021; Accepted 16 July 2021; Published 23 July 2021

Academic Editor: Ehsan Namaziandost

Copyright (C) 2021 Noushin Mousazadeh et al. This is an open access article distributed under the Creative Commons Attribution License, which permits unrestricted use, distribution, and reproduction in any medium, provided the original work is properly cited.

\begin{abstract}
Introduction. Given the vital role of critical thinking and possibility of developing this meta-cognitive skill through training programs, the present study was conducted to determine the tendency and effective factors in critical thinking in nursing students. Materials and Methods. The present study is a cross-sectional study that was conducted in 2020 in a school of nursing in northern Iran. Participants in the study were all second to eighth semester nursing students studying in the faculty who entered the study by the census method. Inclusion criteria included employment in the field of nursing in the second semester and above, and exclusion criteria were employment and incomplete completion of the questionnaire questions. The required information was prepared in two parts: the first part of recording demographic information including age, gender, marital status, semester, average score, previous semester average score, and level of interest in the major and the second part was the adopted Ricketts' critical thinking disposition questionnaire. SPSS 26 software and descriptive and analytical statistics were used to analyze the data. Results. The total average score of critical thinking disposition obtained as $120.20 \pm 14.0535$ was found to positively and significantly relate to age $(r=0.150, p=0.04, d=0.30)$, academic 36 semester $(p=0.001, d=0.25)$, and interest in the major $(p=0.003, d=0.38)$. Dimensions of 37 innovation and maturity were also significantly associated with academic semester and 38 interested in the major. Also, the total score of critical thinking and its dimensions in married people was higher than single, but this difference was not statistically significant. The results of analysis of variance showed that there is a positive and significant relationship between the mean score of tendency to critical thinking and different semesters. Conclusion. Identifying the effective factors in critical thinking disposition can assist teachers in developing lesson plans and academic counseling, and at the macro level, can help with educational planning and revision of curricula.
\end{abstract}

\section{Introduction}

To make the right decisions and provide the best care services, nurses need to know their own emotions and thoughts and those of patients and their families. This kind of decision-making is possible with critical thinking $[1,2]$. What all the numerous definitions proposed for critical thinking have in common is that critical thinking can be developed as a meta-cognitive skill involving rational thinking in the course of educational programs $[3,4]$. Critical thinking is also defined as careful and reflective decision-making to accept, reject, or postpone judgment [5], and nurses with critical thinking can apply their work experiences and properly evaluate research results along with their learning to provide patient care [2]. Nurses are therefore required to develop their critical thinking as an essential part of their professional liability [6-9]. Critical thinking should be taught to nursing students given its vital role in providing patients with health services and solving their problems [5]. The importance of learning critical thinking has caused its integration with nursing curricula since 1989 [3]. The American Nurses Association (1998), the 
National Nurses United (1992), and the Accreditation Commission of the National Nurses United (2002) also proposed learning it as an integral component of nursing education and required nursing instructors to teach it to nursing students [2]. In fact, nursing students should be trained to develop their critical spirit and research capabilities and equip themselves with critical thinking as a valuable tool in a way that their decision-making ability and performance are improved in complicated clinical circumstances after their graduation [10] In this regard, many universities around the world are looking for new and appropriate educational methods that can organize people and their educational system and lead to the expansion and improvement of clinical decision-making, problem solving, and continuous and self-centered learning in medical students. In order to address this concern, supporting critical thinking skills and investing in training and continuous assessment of changes in cognitive processes along with psychomotor and attitudinal domains in caring practices has become particularly important. Promoting this skill 65 undoubtedly improves health services and quality of life and maintains and promotes public health [2].

Promoting this skill undoubtedly improves health services and quality of life and maintains and promotes public health [2]. On the other hand, the absence of critical thinking negatively affects the efficiency, effectiveness, professionalism, independence, and authority of nurses [11]. Nursing instructors are therefore required to broaden their knowledge about critical thinking disposition [12]. Although the research suggests a high score of critical thinking in undergraduate nursing students $[10,13]$, low levels of critical thinking skills have been reported in literature $[6,11,14]$. The effects of individual factors on critical thinking skills have been also reported differently in literature. Some studies suggested insignificant relationships of the critical thinking ability with age and gender in nursing students $[10,15,16]$, whereas other studies showed relationships between gender and critical thinking skills $[5,17]$. The effect of academic year on the tendency towards critical thinking has also been differently reported. Hassanpour et al. reported generally low levels of critical thinking skills and no relationships between academic year and critical thinking skills in nursing students in Iran [18]. A study in Ireland showed lower levels of critical thinking skills in final-year compared to first-year nursing students [12]. Hunter et al. reported relationships between academic year and critical thinking disposition and highest levels of critical thinking in final year students and no relationships between the score of critical thinking skills and demographic variables [3]. Kaya et al. reported moderate levels of critical thinking and no relationships between critical thinking disposition and academic year in nursing students [6]. Moreover, the mean score of critical thinking was found to be higher in students at higher academic years [19], whereas Noon and Seery found first-year nursing students to be stronger critical thinkers than third-year students [12]. No statistically significant relationships were also reported between academic achievement and critical thinking $[10,20]$.

According to the discussed points, the complicated development of thinking skills in students has now turned into a critical issue, which should have been predicted based on serious concerns of education experts about critical thinking inability of students in recent years [12]. According to the UNESCO, as an essential skill of the $21^{\text {st }}$ century, critical thinking is urgently required to be integrated into healthcare and treatment [21]. Paying a special attention to teaching critical thinking skills to nursing students is crucial given the absolutely essential role of critical thinking in nurses, as a large group of health service providers, in providing desirable and high-quality services. Given the different and occasionally contradictory results of research on effective factors in tendency to these skills, the present study was conducted to take a step towards developing and laying plans for critical thinking skills in nursing students by obtaining local data and determining the levels of critical thinking disposition and the relevant factors in nursing students.

\section{Materials and Methods}

The present study is a cross-sectional descriptive study that was conducted from June to August 2020 in a nursing school in northern Iran. The study participants, including all the second to eighth semester nursing students, were selected with the census method. Being a nursing student of at least second semester was the only inclusion criterion and the exclusion criteria comprised being employed and failing to complete the questionnaires. After obtaining permission from the Deputy of Research and Technology and receiving the approval of the Ethics Committee (x.7209) of x, perform the necessary coordination of the researcher with the authorities of the school, as well as previous coordination with the class representative and determine a specific time that was determined by the students of each class, referring to their training classes and introducing themselves, the purpose of the study and how to respond. Explain the questionnaire to the participants and if they want to participate in the study, obtain their informed oral consent; the adopted questionnaire will be given to them and they will be reassured and reminded about anonymity. Not participating in the study will not have any negative consequences on their academic consequences and they can withdraw the study at any time.

The data collected included demographic details such as age, gender, marital status, academic semester, overall GPA, previous semester GPA, and interest in nursing. The second part of the data was collected by completing the 33-item Ricketts' critical thinking disposition questionnaire as a standard self-report for measuring the tendency towards critical thinking. The items were scored on a five-point Likert scale ranging from completely agree to completely disagree. The subscales included innovation (11 items), maturity (9 items), and engagement (13 items) [22, 23]. The present study confirmed the questionnaire reliability by calculating Cronbach's alpha of 0.85 . 
The data were analyzed in SPSS 26, and their distribution normality was assessed using the Kolmogorov-Smirnov test, which suggested a normal distribution for $p>0.05$. Descriptive statistics such as mean, standard deviation, frequency, and relative frequency were then used. The hypotheses were tested using the Pearson correlation coefficient, the independent $t$-test, and one-way ANOVA. The effect size of the significant hypotheses was ultimately determined using Cohen's $d$, with $d=0.1$ suggesting a low effect size, $d=0.3$ medium and $d=0.5$ large in the correlation test, and $d=0.2$ low, $d=0.5$ medium, and $d=0.85$ large in ANOVA [23]. The level of statistical significance was adjusted as $p<0.05$.

\section{Results}

The majority of the 196 participants were female $(n=124)$ and single $(n=174)$. Table 1 summarizes the main demographic data of the students. The total score of critical thinking disposition was obtained as 120.20 ( $\mathrm{SD}=14.05$, $95 \% \mathrm{CI}=118.00-122.41$ ), the score of innovation as 42.06 $(\mathrm{SD}=5.69,95 \% \mathrm{CI}=41.17-42.95)$, that of maturity as 30.49 $(\mathrm{SD}=4.41,95 \% \mathrm{CI}=29.80-31.18)$, and that of engagement as $36.47(\mathrm{SD}=7.10,95 \% \mathrm{CI}=47.48-64.25)$.

The findings suggested that the total score of critical thinking disposition was correlated with only academic semester $(p=0.001, d=0.25)$, interest in nursing $(p=0.003, d=0.38)$, and age $(r=0.150, p=0.04, d=0.30)$.

The total score of critical thinking disposition was higher in the females than males and in the married students than the singles, although the differences were statistically insignificant. Statistically significant differences were, however, observed in engagement between the males and females (Table 2).

According to Table 2, although the total mean score of critical thinking and the scores of maturity and innovation were higher in the female participants than in the males, the differences were statistically insignificant; nevertheless, significant differences were observed in engagement between the females and males $(p=0.01, d=0.06)$. The total score of critical thinking and scores of its dimensions were higher in the married participants compared to in the singles, although the differences were statistically insignificant.

The results of ANOVA showed a positive and significant relationship between the mean score of critical thinking disposition and academic semester. Table 3 provides the highest critical thinking scores in the sixth-semester students and the lowest in the third-semester students.

According to Table 3, academic semester was positively and significantly related to the total score of critical thinking and scores of innovation and maturity. The sixth-semester and third-semester students, respectively, received the highest and lowest engagement scores, although the difference was statistically insignificant.

Interest in the major was positively and significantly related to critical thinking disposition. Table 4 provides the total score of critical thinking disposition and scores of its dimensions by interest in the major.
The results showed interest in nursing to be positively and significantly associated with the total score of critical thinking disposition and scores of innovation and maturity, although this relationship was insignificant for the dimension of engagement.

\section{Discussion}

The present research was conducted to investigate critical thinking disposition and its effective factors in nursing students. The total score of critical thinking disposition was obtained as 120.2 out of 200 . The present findings are generally different from those obtained in other studies. For example, Azizi-Fini et al. reported mean critical thinking scores were $11.79 \pm 4.80$ and $11.21 \pm 3.17$ out of 34 for the freshmen and the senior students, respectively $(p=0.511)$ [21]. Also, Orujlu and Hemmati Maslakpak reported this amount (10.56 \pm 4.67 ) (out of 34) [5]. Salahshoor and Rafiee believed that there is not enough satisfaction of Iranian students' critical thinking [22]. It seems that the reason is due to deficiency of enough thinking skills in educational systems of Iran [22].

As Hunter et al. said, we must pay attention to the fact that comparing the score of critical thinking between different studies does not yield the right results given the different instruments with different subscales and scoring systems used in these studies [3].

Today's constantly advancing technologies coupled with the increasing complexity of conditions of patients with different cultural backgrounds facing nurses require their independent and sometimes spontaneous decision-making. Critical thinking in nursing students as future nurses ensures their better and more appropriate decisions in strategic situations. A review of literature suggests teaching methods used in Iranian nursing schools focus on strengthening theoretical background in nursing students without developing their critical thinking and problem-solving skills, which lowers their critical thinking capability [21].

In this study, among different effective factors in critical thinking, academic semester, interest in the profession, and age were found to significantly relate to the total score of critical thinking disposition. In contrast, Azizi-Fini et al. showed that there is an insignificant correlation between nursing students' critical thinking and age, gender, and interest in the profession [21]. Different statistical population, study design, and different educational background involved in this results.

The present study reported a significant relationship between critical thinking and academic semester in a way that the sixth-semester students had the highest level of critical thinking. This relationship suggests nursing education in the school has improved and strengthened critical thinking in the students. Participation of nursing students according to Iranian educational curricula in both theoretical classes and clinical training programs under the direct supervision of an instructor before the seventh semester integrates their theoretical teachings with clinical experiences and develops their critical thinking.

The present study found declining in critical thinking in the seventh and eighth semesters. While when the years of 
TABLE 1: Demographic details of the study subjects.

\begin{tabular}{lc}
\hline Demographic details & $N(\%)$ \\
\hline Gender & $124(63.3)$ \\
Female & $72(36.7)$ \\
$\quad$ Male & $22(11.2)$ \\
\hline Marital status & $174(88.8)$ \\
$\quad$ Married & $39(19.9)$ \\
$\quad$ Single & $111(56.6)$ \\
\hline Interest in the major & $46(23.5)$ \\
$\quad$ Low & Mean (SD) \\
Moderate & $21.68(2.09)$ \\
$\quad$ High & $16.23(1.35)$ \\
\hline Age & \\
Total average score &
\end{tabular}

TABLE 2: Total score of critical thinking disposition and scores of its dimensions by gender and marital status.

\begin{tabular}{|c|c|c|c|c|c|c|}
\hline \multirow{3}{*}{ Independent variable/critical thinking disposition } & \multirow{2}{*}{\multicolumn{2}{|c|}{$\begin{array}{c}\text { Gender } \\
\text { Mean } \pm \text { SD }\end{array}$}} & \multicolumn{4}{|c|}{ Marital status } \\
\hline & & & \multirow[t]{2}{*}{$P$} & \multicolumn{2}{|c|}{ Mean \pm SD } & \multirow[t]{2}{*}{$P$} \\
\hline & Female & Male & & Female & Male & \\
\hline Innovation & $42.04 \pm 5.50$ & $41.92 \pm 5.71$ & 0.69 & $41.92 \pm 5.41$ & $42.57 \pm 6.74$ & 0.25 \\
\hline Maturity & $30.64 \pm 4.47$ & $29.34 \pm 4.41$ & 0.66 & $30.11 \pm 4.58$ & $30.44 \pm 3.70$ & 0.19 \\
\hline Engagement & $47.38 \pm 6.45$ & $46.91 \pm 8.91$ & 0.01 & $46.93 \pm 7.49$ & $49.19 \pm 7.09$ & 0.99 \\
\hline Total & $118.46 \pm 13.06$ & $117.55 \pm 22.17$ & 0.08 & $117.78 \pm 14.56$ & $120.92 \pm 15.76$ & 0.45 \\
\hline
\end{tabular}

TABle 3: Total score of critical thinking disposition and scores of its dimensions in different semesters.

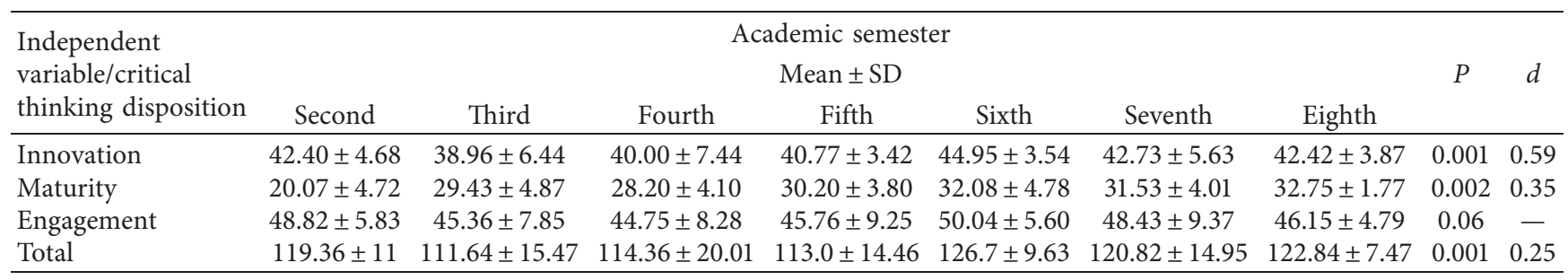

TABLE 4: Total score of critical thinking disposition and scores of its dimensions by interest in the major.

\begin{tabular}{|c|c|c|c|c|c|}
\hline \multirow{3}{*}{ Independent variable/critical thinking disposition } & \multicolumn{3}{|c|}{ Interest in the major } & \multirow{3}{*}{$P$} & \multirow{3}{*}{$d$} \\
\hline & & Mean \pm SD & & & \\
\hline & Low & Moderate & High & & \\
\hline Innovation & $39.83 \pm 6.46$ & $42.12 \pm 5.15$ & $43.47 \pm 5.28$ & 0.01 & 0.22 \\
\hline Maturity & $27.97 \pm 4.40$ & $30.86 \pm 4.07$ & $30.36 \pm 4.95$ & 0.003 & 0.26 \\
\hline Engagement & $45.17 \pm 7.34$ & $47.07 \pm 7.71$ & $48.97 \pm 6.73$ & 0.07 & - \\
\hline Total & $117.79 \pm 12$ & $118.48 \pm 15.61$ & $122.67 \pm 12.19$ & 0.003 & 0.38 \\
\hline
\end{tabular}

academic education increase, capacity of knowledge and then capacity of critical thinking increase [2]. But this opposite result can be a complication of the lack of direct supervision of the instructor in the internship and the students' absence from the school, which keeps them away from books and prevents their updating and causes them to perform routine internship tasks. It is recommended that further studies be conducted to elucidate this finding and investigate the effects of strategies such as using modern and evidence-based teaching methods and student-oriented evaluation on critical thinking in the students of these semesters.

Contradictory findings have been reported on this subject in literature. In contrast to the present research, a study by Hassanpour et al. found no relationships between academic year and critical thinking skills [17], and a study by Kaya et al. showed moderate levels of critical thinking and no relationships between academic year and critical thinking disposition in nursing students [6]. Arli et al. found a significant decrease in critical thinking average when the year of study decreases [2]. 
In line with the present study suggesting significant relationships between academic semester and critical thinking, a study by Noon and Seery found lower levels of critical thinking skills in Irish final-year nursing students compared to in first-year students [12]. These discrepancies in results can be explained by differences in theoretical and clinical teaching context associated with a specific teachinglearning style and the supportive context in which students learn critical thinking. Different university admission criteria can also result in admitting nursing students with diverse and different backgrounds, including learning styles, which should be confirmed by performing comprehensive research.

The present study showed significant relationships between interest in the major and critical thinking disposition. Having interest in the major creates internal motivation in students and therefore encourages them to make efforts to learn and promote their critical thinking, which itself needs motivation. In contrast, Azizi-Fini et al. reported no significant relationships between interest in the major and critical thinking [21]. This difference can be explained by the effects of other factors such as teaching styles and educational environments on this relationship.

The positive and significant relationship between age and critical thinking reported in the present research and studies by Hassanpour et al. [18] and Karadege et al. [2] can be explained by the higher effectiveness of environmental trainings in older students and their higher educational and clinical experiences. In contrast, Harrison [16], Hunter et al. [3], Hassanpour et al. [17], and Mousazadeh et al. [10] reported no relationships between age and critical thinking.

The present findings suggested significant differences between the two genders only in terms of engagement dimension of critical thinking. Harrison found gender not to affect critical thinking [16]. Salahshor and Refaie also reported insignificant differences in critical thinking between two genders [22]. Orujlu and Hemmati Maslakpak and also Mousazadeh et al. stated that there was no significant difference in critical thinking between the male and female [10]. This research suggests insignificant differences between two genders in terms of critical thinking and that gender alone cannot predict critical thinking and "role-playing in one's own gender" significantly promotes critical thinking [24]. Although nursing is considered a feminine profession, many men also serve in this profession. Nursing educators are therefore required to pay attention to the features of both genders in developing critical thinking. However, there are contrast results like Hassanpour et al. reported that there was a significant difference between critical thinking in two gender. It seems more studies are needed [17].

\section{Conclusions}

Several effective factors in critical thinking identified in the present study should be considered by the authorities and faculty of nursing schools. As a prerequisite for making decisions in complicated and emergency situations, critical thinking significantly affects the quality and quantity of nursing services. To honor their commitment to the community, i.e., training competent nurses, nursing schools should incorporate these and similar factors found in other studies to their educational strategies.

The present study investigated several factors affecting critical thinking in nursing students. It is recommended that similar studies be conducted in different universities given the potential effects of many factors such as educational environment and its atmosphere, social structure of educational environment, technologies employed in teaching, and cultural context on critical thinking disposition. The present study limitations included its small sample and using the census method and a cross-sectional instead of longitudinal design $[23,24]$.

\section{Data Availability}

The datasets analyzed during this study are available from the corresponding author upon request.

\section{Conflicts of Interest}

The authors declare that they have no conflicts of interest.

\section{Acknowledgments}

This study was supported by a research project approved by the Mazandaran University of Medical Sciences (Code no. 7209). The authors would like to express their gratitude to all the participating students and other officials who helped conduct this study as well as the Research Deputy of Mazandaran University of Medical Sciences for funding this project.

\section{References}

[1] M. Heffernan, M. T. Quinn Griffin, S. R. McNulty, and J. J. Fitzpatrick, "Self-compassion and emotional intelligence in nurses," International Journal of Nursing Practice, vol. 16, no. 4, pp. 366-373, 2010.

[2] S. K. Arli, A. B. Bakan, S. Ozturk, E. Erisik, and Z. Yildirim, "Critical thinking and caring in nursing students," International Journal of Caring Sciences, vol. 10, no. 1, p. 471, 2017.

[3] S. Hunter, V. Pitt, N. Croce, and J. Roche, "Critical thinking skills of undergraduate nursing students: description and demographic predictors," Nurse Education Today, vol. 34, no. 5, pp. 809-814, 2014.

[4] P. A. Riccio, "Predictors of improvement in critical thinking skills among nursing students in an online graduate nursing research course," Universal Journal of Educational Research, vol. 3, no. 9, pp. 606-609, 2015.

[5] S. Orujlu and M. H. Maslakpak, "Assessing the relationship between critical thinking and self-efficacy of nursing student," Journal of Nursing Education, vol. 5, no. 6, pp. 11-17, 2017.

[6] H. Kaya, E. Şenyuva, and G. Bodur, "Developing critical thinking disposition and emotional intelligence of nursing students: a longitudinal research," Nurse Education Today, vol. 48, pp. 72-77, 2017.

[7] J. J. Hoffman, "Teaching strategies to facilitate nursing students' critical thinking," Annual Review of Nursing Education, vol. 6, p. 225, 2008.

[8] R. Y. Wood and C. E. Toronto, "Measuring critical thinking dispositions of novice nursing students using human patient 
simulators," Journal of Nursing Education, vol. 51, no. 6, pp. 349-352, 2012.

[9] D. M. Zygmont and K. M. Schaefer, "Assessing the critical thinking skills of faculty: what do the findings mean for nursing education?" Nursing Education Perspectives, vol. 27, no. 5, pp. 260-268, 2006.

[10] S. Mousazadeh, M. Momennasab, T. Bakhtiari, and M. Reisi, "Nursing students' disposition toward critical thinking and its relationship with their academic performance," Nursing, vol. 5, no. 4, 2016.

[11] Y. Kanbay, E. Isik, E. Işik, Ö. Aslan, P. Tektaş, and N. Kiliç, "Critical thinking skill and academic achievement development in nursing students: four-year longitudinal study," American Journal of Educational Research and Reviews, vol. 2, no. 12, pp. 1-10, 2017.

[12] T. Noone and A. Seery, "Critical thinking dispositions in undergraduate nursing students: a case study approach," Nurse Education Today, vol. 68, pp. 203-207, 2018.

[13] A. R. Kabeel and S. A. E.-M. M. Eisa, "The correlation of critical thinking disposition and approaches to learning among baccalaureate nursing students," Journal of Education and Practice, vol. 7, no. 32, pp. 91-103, 2016.

[14] N.-Y. Liu, W.-Y. Hsu, C.-A. Hung, P.-L. Wu, and H.-C. Pai, "The effect of gender role orientation on student nurses' caring behaviour and critical thinking," International Journal of Nursing Studies, vol. 89, pp. 18-23, 2019.

[15] I. N. Ghadi, K. A. Bakar, N. H. Alwi, and O. Talib, "Gender analysis of critical thinking disposition instrument among University Putra Malaysia Undergraduate Students," Recent Technological Advances in Education, vol. 2, pp. 7-33, 2012.

[16] J. Harrison, "Student nurses' gender role is a predictor of caring behaviours and critical thinking," Evidence Based Nursing, vol. 22, 2019.

[17] M. Hasanpour, A. Hasanzadeh, F. Ghaedi Heidari, and M. Bagheri, "Critical thinking skills of nursing students," Iran Journal of Nursing, vol. 28, no. 93, pp. 22-31, 2015.

[18] C. Thongnuypram and S. Sopheerak, "Factor influencing the critical thinking of teacher students studying at the faculty of education in suratthani rajabhat university," Procedia-Social and Behavioral Sciences, vol. 103, pp. 386-391, 2013.

[19] S. Emir, "Education faculty students' critical thinking disposition according to achedemic achievement," ProcediaSocial and Behavioral Sciences, vol. 1, no. 1, pp. 2466-2469, 2009.

[20] H. Khalili, "Critical thinking skills of nursing students in semnan university of medical Sciences," Iranian Journal of Medical Education, vol. 4, no. 2, pp. 23-31, 2004.

[21] I. Azizi-Fini, A. Hajibagheri, and M. Adib-Hajbaghery, "Critical thinking skills in nursing students: a comparison between freshmen and senior students," Nursing and Midwifery Studies, vol. 4, no. 1, 2015.

[22] N. Salahshoor and M. Rafiee, "The relationship between critical thinking and gender: a case of Iranian efl learners," Journal of Applied Linguistics and Language Research, vol. 3, no. 2, pp. 117-123, 2016.

[23] J. C. Ricketts, The Efficacy of Leadership Development, Critical Thinking Dispositions, and Student Academic Performance on the Critical Thinking Skills of Selected Youth Leaders, University of Florida, Gainesville, FL, USA, 2003.

[24] S. S. Sawilowsky, "New effect size rules of thumb," Journal of Modern Applied Statistical Methods, vol. 8, no. 2, p. 26, 2009. 